\title{
Relationship Between Thyroid Hormone Levels and Mean Platelet Count and Volume: Quantitative Assessment
}

\author{
Sardar H. Ijaz ${ }^{1}$, Shakeel M. Jamal ${ }^{2}$, Rehan Qayyum ${ }^{3}$
}

1. Internal Medicine, Oklahoma University of Health Sciences, Oklahoma City, USA 2. Internal Medicine, Central Michigan University College of Medicine, Saginaw, USA 3. Internal Medicine, Virginia Commonwealth University, Richmond, USA

$\square$ Corresponding author: Sardar H. Ijaz, sardar-ijaz@ouhsc.edu Disclosures can be found in Additional Information at the end of the article

\section{Abstract}

\section{Background}

The hormones of the hypophysis-thyroid axis (HTA), thyroid stimulating hormone (TSH), and thyroid hormones, L-thyroxine (T4) and 3, 3', 5-L-triiodothyronine (T3), modulate the metabolism, differentiation, and proliferation of almost every cell in the body. Several studies have examined the effect of HTA hormones on platelet count and mean platelet volume (MPV), but have reported inconsistent results. Our aim was to examine the association between HTA hormones and platelet count and MPV in a large cohort of the adult population of the United States.

\section{Methods}

We used the continuous National Health and Nutritional Examination Survey (NHANES) which made available data on HTA hormones (1999-2000, 2001-2002, 2007-2008, 2009-2010, and 2011-2012) to examine the association between HTA hormones and platelet count and MPV. Analyses were performed with adjustments for the complex survey sampling methods of NHANES data. Unadjusted and adjusted generalized linear regressions were performed to examine the relationship between HTA hormones and platelet count and MPV. Regression models were adjusted for age, sex, race, alcohol use, smoking status, serum c-reactive protein, red blood cell folate, diabetes mellitus, glomerular filtration rate, body mass index, and hypertension.

\section{Results}

Received 08/07/2018 Review began 08/14/2018 Review ended 09/29/2018 Published 10/08/2018

\section{(c) Copyright 2018}

ljaz et al. This is an open access article distributed under the terms of the Creative Commons Attribution License CC-BY 3.0., which permits unrestricted use, distribution, and reproduction in any medium, provided the original author and source are credited.
Of the 10,619 individuals eligible for inclusion in the analyses, 5,267 (49.6\%) were females and 2,132 (20.08\%) were African Americans. The mean \pm standard deviation of platelet count was $256.4 \pm 67.110^{9} / \mathrm{L}, \mathrm{MPV} 8.04 \pm 0.92 \mathrm{fL}$, serum T4 $7.92 \pm 1.68 \mathrm{mg} / \mathrm{dL}$, and serum T3 $114.08 \pm 24.6$ $\mathrm{ng} / \mathrm{dL}$. In unadjusted analyses, an increase in the serum levels of T4 or T3 was associated with a significant increase in the platelet count and MPV (all $p$-values $<0.05$ ). In contrast, an increase in serum TSH level was associated with a significant decrease in the platelet count ( $p$-value = 0.05 ) but had no effect on MPV. After adjustment for potential confounders, serum T4 levels were significantly associated with platelet count but not with MPV. Individuals in the lowest quartile of T4 had $18.73 \times 10^{9} / \mathrm{L}$ lower platelet count than individuals in the upper-most quartile $(p$-value $=0.03)$. Serum TSH and serum T3 levels had no effect on platelet count or MPV after adjusting for potential confounding variables. 


\section{Conclusions}

We report that only serum T4 levels, and not TSH or T3 levels, are independently associated with platelet count and there is no independent association between HTA hormones and MPV. Our findings suggest a possible role of serum T4 on thrombopoiesis or on platelet lifespan.

Categories: Cardiology, Endocrinology/Diabetes/Metabolism, Internal Medicine

Keywords: mean platelet volume, platelet count, thyroid hormone

\section{Introduction}

Platelets play an essential role in maintaining hemostasis and the vascular endothelium and in wound healing [1]. Platelet production or thrombopoiesis is a unique process in which a small number of megakaryocytes within bone marrow produce a large number of circulating platelets. A fine balance between thrombopoiesis and platelet apoptosis maintains the platelet count in blood, and various endogenous and exogenous factors can alter this balance [2-3].

Thyroid hormones, L-thyroxine (T4) and 3, 3', 5-L-triiodothyronine (T3), modulate the metabolism, differentiation, and proliferation of almost every cell in the body [4]. Their production is regulated through a negative feedback mechanism by the hypothalamus-pituitary axis via thyroid stimulating hormone (TSH) [5]. Thyroid hormones mainly act via intranuclear thyroid receptors (TR), which combine with retinoid X receptors (RXR) to form a heterodimer. This heterodimer interacts with the thyroid response elements (TRE)-specific regulatory regions of genes in deoxyribonucleic acid (DNA) to modulate gene expression [6].

Thyroid hormone receptors are present on hematopoietic stem cells and serum levels of thyroid hormone may modulate the production of blood cells including platelets [7]. However, clinical studies have shown inconsistent associations between thyroid hormone levels and platelet count and mean platelet volume (MPV) [8-11]. Most of these studies were small and enrolled patients with clinical thyroid disease. Therefore, our objective was to examine the relationship between serum thyroid hormone levels (T4, T3, and TSH) and platelet count and MPV in a large cohort of adults without the history of thyroid disease.

\section{Materials And Methods}

\section{Study population}

We used the continuous National Health and Nutritional Examination Survey (NHANES) to examine the association between thyroid hormones status and platelet count and MPV. The detailed methods for this survey are available online and briefly summarized here [12]. The continuous NHANES is a complex, stratified, multistage probability cluster conducted at regular intervals and is designed to be representative of the civilian, non-institutionalized US population. For each survey period, data are collected via household interviews and standardized physical examinations conducted in specially equipped mobile examination centers.

We used those two-year survey periods for which data on thyroid hormone status were available (1999-2000, 2001-2002, 2007-2008, 2009-2010, and 2011-2012). Thyroid hormone levels were not measured during the 2003-2004 and 2005-2006 survey cycles. Participants who were older than 20 years, were free of clinical thyroid problems (answered 'no' to the question “ever told you had a thyroid problem/disease") and had data on platelet count and thyroid hormones were included in the study. 


\section{Study measurements}

The demographic information was ascertained from self-reported responses to the questionnaire administered by trained interviewers. Body mass index (BMI) was calculated by dividing body weight in kilograms with height in meters. Blood pressure (BP) was calculated as an average of up to four readings. Hypertension was defined as a mean systolic BP of $140 \mathrm{mmHg}$ or greater, a mean diastolic BP of $90 \mathrm{mmHg}$ or greater, or a diagnosis of hypertension [13]. Based on alcohol intake, participants were categorized into non-drinkers, light drinkers ( $\leqslant 5$ drinks/week), or heavy drinkers ( $>5$ drinks/week). Participants who were active smokers were categorized as current smokers, and participants who had either quit smoking or had never smoked were categorized as non-current smokers.

Blood counts, including platelet counts, were measured using Beckman Coulter Counter (Beckman Coulter Inc., Brea, CA, USA). Serum TSH was measured using the Access HYPERsensitive human thyroid-stimulating hormone (hTSH) assay (Beckman Coulter Inc., Brea, CA, USA) which uses a two-site immunoenzymatic ("sandwich”) technique. Serum T3 and T4 were measured by a competitive binding immunoenzymatic technique using the Access Total T4 and the Access Total T3 assays (Beckman Coulter Inc., Brea, CA, USA). T4 measurements in 2011-2012 were adjusted to compare with the rest of the survey periods. Serum C-reactive protein (CRP) levels were quantified using latex-enhanced nephelometry and a Behring Nephelometer II Analyzer (Behring Diagnostics, Somerville, NJ, USA). Serum creatinine was measured using the Jaffe rate method (kinetic alkaline picrate). Glomerular filtration rate (GFR) was calculated using the Chronic Kidney Disease Epidemiology Collaboration (CKD-EPI) equation [14]. Urine iodine concentrations were determined by inductively coupled plasma dynamic reaction cell mass spectroscopy (ICP-DRC-MS), which uses a multi-element analytical technique. Serum glucose was measured using a hexokinasemediated reaction and blood glucose level was measured using the Beckman Synchron LX20 test (Beckman Coulter, Brea, CA, USA) on refrigerated specimens. Glycohemoglobin was measured directly using boronate affinity high-performance liquid chromatography (HPLC). Diabetes mellitus was defined as a diagnosis of diabetes mellitus, a glycohemoglobin $>6.5 \%$, a fasting blood glucose $>126 \mathrm{mg} / \mathrm{dL}$, or a random blood glucose $>200 \mathrm{mg} / \mathrm{dL}$ [15]. Red blood cell (RBC) folate levels were measured using the Bio-Rad Quanta phase II competitive proteinbinding measurement procedure (Bio-Rad Laboratories, Hercules, CA, USA) from 1999 to 2002, or using microbiological assays from 2007 to 2012. RBC folate levels were adjusted for change in the measurement methods [16].

As different measures of iron status were available for different individuals, we used an algorithmic approach and used the next step in the algorithm only when data were not available for that particular step. A participant was defined as iron deficient if the ratio of soluble transferrin receptor (sTfR) to log10 (ferritin) was more than 1.36 [17]. If no data were available on soluble transferrin receptor, then iron deficiency was defined by transferrin saturation < $15 \%$, serum ferritin $<12 \mathrm{ug} / \mathrm{mL}$, and serum protoporphyrin $>1.24 \mathrm{umol} / \mathrm{L}$. If there was no data on serum ferritin, transferrin saturation, or serum protoporphyrin, then iron deficiency was defined as either a transferrin saturation $<15 \%$ and serum protoporphyrin $>1.24 \mathrm{umol} / \mathrm{L}$, or serum ferritin < $12 \mathrm{ng} / \mathrm{mL}$ and serum protoporphyrin $>1.24 \mathrm{umol} / \mathrm{L}$, or transferrin saturation < $15 \%$ and serum ferritin < $12 \mathrm{ug} / \mathrm{mL}$ [18]. Soluble transferrin receptor levels were measured using the Tina-quant sTfR assay (Roche Diagnostics, Mannheim, Germany), an automated homogeneous immunoturbidimetric assay (Hitachi 912 clinical analyzer, Roche Diagnostics, Indianapolis, IN, USA). Serum ferritin was measured using the Bio-Rad Laboratories' "QuantImune Ferritin IRMA" kit (BioRad Laboratories, Hercules, CA, USA), a single-incubation two-site immunoradiometric assay (IRMA), from 1999 to 2002, and using the Roche Tina-quant ferritin immunoturbidimetric assay on the Hitachi 912 clinical analyzer (Roche Diagnostics, Indianapolis, IN, USA) from 2007 to 2012. Ferritin values were adjusted for 1999-2000, 20012002, and 2007-2008 to match 2009-2010 and 2011-2012 measurements. Free erythrocyte 
protoporphyrin was quantitatively determined by molecular fluorometry using a

spectrofluorometer. Transferrin saturation was calculated by dividing serum iron by total ironbinding capacity (TIBC). Iron and TIBC were measured on an Alpkem Flow Solutions IV (rapidflow analysis) system.

\section{Statistical analyses}

Analyses were performed with adjustments for the complex survey sampling methods of NHANES data. In continuous NHANES, primary sampling units represent variance (sampling units used to estimate sampling error) units. Participants were oversampled for certain population subgroups such as African and Mexican Americans to ensure the reliability and precision of health estimate indicators in these subgroups. The sampling weights, and where needed subsample weights, were assigned to each person, reflecting the adjustment for the unequal probability of selection, nonresponse, and adjustments to independent population controls. Sample weights were constructed with the rescaling of weights such that the sum of weights matched the survey population at the midpoint of each two-year survey period. For this study, sample weights were constructed for 10 years of combined survey data. All statistical analyses were performed in the R statistical language (version 3.1.0) using the survey package (version 3.29) to account for the complex survey design.

Data were summarized as the mean and standard deviation, median and interquartile range, or percentages as appropriate. Although we excluded individuals with the history of thyroid disease, individuals may have subclinical disease. Therefore, we excluded individuals with serum TSH less than 0.1 or greater than 4.5 when examining the relationship between serum TSH and platelet indices. For total and free T3 and T4, we excluded individuals who were at the extreme $1 \%$ of the respective distributions. To examine the relationship independent of distributional assumptions, we also examined the relationship between quartiles of thyroid hormones and platelet indices. The distributions of serum CRP and RBC folate were rightskewed and these variables were log-transformed before analyses. Quartile cut points for TSH, $\mathrm{T} 4$, and $\mathrm{T} 3$ were based on weighted distributions in the whole study sample. Unadjusted and adjusted generalized linear regression models were built to examine the relationship between thyroid hormones and platelet count and MPV. Regression models were adjusted for age, sex, race, the extent of alcohol use, smoking status, serum CRP, RBC folate, diabetes mellitus, GFR, BMI, and hypertension. Data on iron deficiency was available on 4,513 individuals and in that subset, we included the iron deficiency in the model to examine its effect.

\section{Results}

The data from the 10-year period (1999-2002 and 2007-2012) included 51,446 individuals. We excluded 23,442 individuals for age $<20$ years, 2,398 individuals for personal history of thyroid problems, 14,987 individuals for missing at least one serum thyroid hormone level platelet count, or MPV. Data on serum free T4, T3, and free T3 was available for a six-year period only (2007-2012) enrolling 7,781 participants. Of the 10,619 individuals included in the analyses, 5,008 (48.8\%) were females, 2,016 (19.6\%) were African Americans, 2,231 (21.8\%) were current smokers, and 820 (9.4\%) were heavy drinkers. The mean \pm standard deviation age of participants was $49.4 \pm 17.7$ years, platelet count 256.7 \pm 67.2 109/L, MPV 8.04 $\pm 0.92 \mathrm{fL}$, serum total T4 $7.9 \pm 1.5 \mathrm{mg} / \mathrm{dL}$, serum free T4 $0.79 \pm 0.12 \mathrm{ng} / \mathrm{dL}$, serum total T3 $113.4 \pm 20.4 \mathrm{ng} / \mathrm{dL}$, serum free T3 $3.17 \pm 0.34 \mathrm{pg} / \mathrm{mL}$, and serum TSH levels 1.68 (0.87) mIU/mL (Table 1). When examined by quartiles of total T4 levels, there were more females, nonsmokers, hypertensives, and diabetics in the highest quartiles of T4 than in the lowest quartile (Table 2). Similarly, individuals in the highest total T4 quartile had a higher BMI, platelet count, and mean platelet volume. However, there was no difference in age, GFR, and RBC folate among total T4 quartiles (Table 1). 


\section{Cureus}

\section{VARIABLES}

Age in years, $\mathrm{n}(\mathrm{SD})$

Age categories

Elderly ( $\geq 60$ years), n(SD)

Middle age (40-59 years), $n(S D)$

Young (<40 years), n(SD)

Female, n(SD)

Race categories $\mathrm{n}(\mathrm{SD})$

White

Black

Hispanic

Other

Alcohol usage categories, $n(S D)$

\section{Heavy drinker}

Lightdrinker

Non-Drinker

Hypertension, n(SD)

Diabetes mellitus, $\mathrm{n}(\mathrm{SD})$

Smoker, n(SD)

BMI $\left(\mathrm{kg} / \mathrm{m}^{2}\right), \mathrm{n}(\mathrm{SD})$

RBC folate, $n(S D)$

GFR (ml/min), n(SD)

TSH (ulU/mL), n(SD)

T4 (ug/mL), n(SD)

Free T4 (ng/dL), n(SD)

T3 (ng/dL), n(SD)
T4 Quartile 1 T4 Quartile 2

3

$49.17(17.45) \quad 49.49(17.43)$

$\begin{array}{ll}49.68 & 49.18 \\ (17.52) & (18.28)\end{array}$

$\begin{array}{llllll}742(28.91) & 776(30.22) & 837(31.41) & 789(32.01) & 3,144(30.63) & 0.009 \\ 880(34.28) & 868(33.8) & 870(32.65) & 731(29.66) & 3,349(32.63) & \\ 945(36.81) & 924(35.98) & 958(35.95) & 945(38.34) & 3,772(36.75) & \\ & & 1,335 & 1,453 & & \\ 1,002(39.03) & 1,218(47.43) & (50.09) & (58.95) & 5,008(48.79) & <0.001\end{array}$

$\begin{array}{llllll}1,343(52.32) & 1,212(47.2) & \begin{array}{l}1,172 \\ (43.98)\end{array} & 967(39.23) & 4,694(45.73) & <0.001 \\ 558(21.74) & 493(19.2) & 506(18.99) & 459(18.62) & 2,016(19.64) \\ 538(20.96) & 695(27.06) & 814(30.54) & 856(34.73) & 2,903(28.28) \\ 128(4.99) & 168(6.54) & 173(6.49) & 183(7.42) & 652(6.35)\end{array}$

$245(11.03) \quad 224(10.19) \quad 199(8.88) \quad 152(7.33) \quad 820(9.39) \quad<0.001$

$\begin{array}{lllll}1,750(78.76) & 1,659(75.44) & 1,679 & 1,512 & 6,600(75.55)\end{array}$

$227(10.22) \quad 316(14.37) \quad 364(16.24) \quad 409(19.73) \quad 1,316(15.06)$

$907(35.33) \quad 881(34.31) \quad 968(36.32) \quad 965(39.15) \quad 3,721(36.25) \quad 0.003$

$251(9.78) \quad 286(11.14) \quad 354(13.28) \quad 393(15.94) \quad 1,284(12.51) \quad<0.001$

$642(25.03) \quad 540(21.04) \quad 575(21.59) \quad 474(19.26) \quad 2,231(21.76) \quad<0.001$

$27.77(5.84) \quad 28.6(6.31) \quad 28.89(6.47) \quad 29.57(7.2) \quad 28.7(6.5) \quad<0.001$

$\begin{array}{llllll}1,024.5 & 1,026.7 & 1,016 & 998.7 & 1,016.6 & 0.28 \\ (587.1) & (540.2) & (548.6) & (573.6) & (562.5) & \end{array}$

$\begin{array}{llllll}95.12(22.71) & 94.73(22.43) & 94.44 & 94.29 & 94.64(23.86) & 0.67\end{array}$

$1.74(0.9) \quad 1.69(0.85) \quad 1.67(0.86) \quad 1.61(0.84) \quad 1.68(0.87) \quad<0.001$

$6.14(0.54) \quad 7.31(0.26) \quad 8.27(0.3) \quad 9.94(0.92) \quad 7.9(1.49) \quad<0.001$

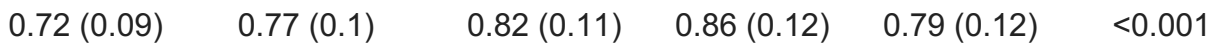

$105.2(17.4) \quad 110.8(18) \quad 115.8(19.2) \quad 122.6(22.9) \quad 113.4(20.4) \quad<0.001$ 


\section{Cureus}

Free T3 (pg/mL), n(SD)

Platelet count $\left(10^{9} / \mathrm{L}\right), \mathrm{n}(\mathrm{SD})$

Mean platelet volume $\left(10^{-15} \mathrm{~L}\right)$

$\mathrm{n}(\mathrm{SD})$
$3.1(0.32)$

$3.14(0.32)$

$250.1(64.9)$

$253.9(65.2)$

$7.98(0.89)$

$3.2(0.34)$

$3.24(0.35)$

$3.17(0.34)$

$<0.001$

$256.7(67.2) \quad<0.001$

\section{TABLE 1: Relationship between thyroid hormones and other variables}

BMI: body mass index; RBC: red blood cell; GFR: glomerular filtration rate; TSH: thyroid stimulating hormone; T4: L-thyroxine; T3: 3, 3', 5-L-triiodothyronine; SD: standard deviation

\section{Platelet Count $\left(10^{3}\right.$ platelets/uL)}

Unadjusted

Mean difference $(95 \% \mathrm{Cl})$
Adjusted

\section{Mean}

value

Cl)

\section{Mean Platelet Volume (attoliters)}

Unadjusted

Mean

difference

$(95 \% \mathrm{Cl})$

Adjusted

Mean

value

difference (95\% Cl) P. value

TSH (ulU/mL)

TSH

TSH Q1

TSH Q2

TSH Q3

TSH Q4 2.59) $-3.35(-5.45$ to 1.26) 0.002 $-2.09(-4.29$ to $0.11)$

0.06

REF

$-6.31(-12$ to -

$0.62)$

0.03

$-4.97(-11.05$ to

1.11)

0.11

$-6.27(-11.35$ to $-\quad 0.02$ 1.19)

$-0.94)$

$-5.83(-10.92$ to $-0.73)$
$-6.66(-12.37$ to 0.02
$-3.48(-35.69$ to 28.72)

REF

55.01 (-24.68

to 134.7$)$

99.53 (30.36 to

168.69)

$-5(-84.23$ to $74.24)$
$12.28(-21.8$

to 46.36$)$

REF

$92.21(-1.2$ to 0.05

185.62)

103.72

(24.62 to

182.82)

$49.73(-30.38$

to 129.85$)$

0.47
0.90

Serum T4

(ug/mL)

\begin{tabular}{|c|c|c|c|c|}
\hline T4 & $\begin{array}{l}4.09 \text { (2.9 to } \\
5.27)\end{array}$ & $<0.001$ & $\begin{array}{l}2.03(0.7 \text { to } \\
3.36)\end{array}$ & 0.003 \\
\hline T4 Q1 & REF & & REF & \\
\hline T4 Q2 & $\begin{array}{l}4.6(0.11 \text { to } \\
9.08)\end{array}$ & 0.04 & $\begin{array}{l}2.07(-2.53 \text { to } \\
6.67)\end{array}$ & 0.37 \\
\hline T4 Q3 & 9.88 (5 to 14.76$)$ & $<0.001$ & $\begin{array}{l}4.07(-1.06 \text { to } \\
9.21)\end{array}$ & 0.12 \\
\hline T4 Q4 & $\begin{array}{l}15.65 \text { (10.5 to } \\
20.79)\end{array}$ & $<0.001$ & $\begin{array}{l}7.83(1.84 \text { to } \\
13.82)\end{array}$ & 0.01 \\
\hline
\end{tabular}

28.12 (9.67 to $\quad 0.003$ 46.56)

REF

$39.38(-32.76$

to 111.52$)$

$47.76(-34.24$

to 129.75$)$

$102.38(28.49$

to 176.28$)$

0.007
$30.92(6.44$ to 55.39 )

REF

$34.31(-57.51$

to 126.14$)$

$74.23(-25.29$

to 173.75$)$

0.14

109.64 (1.1 to 218.18$)$

0.01

0.46 


\section{Cureus}

\section{Serum Free}

T4 (ng/dL)

\begin{tabular}{|c|c|c|c|c|c|c|c|c|}
\hline Free T4 & $\begin{array}{l}-27.84(-47.27 \text { to } \\
-8.42)\end{array}$ & 0.006 & $\begin{array}{l}-18.87(-39.39 \\
\text { to } 1.65)\end{array}$ & 0.07 & $\begin{array}{l}544.08(191.9 \\
\text { to } 896.26)\end{array}$ & 0.003 & $\begin{array}{l}534.48 \\
(151.85 \text { to } \\
917.11)\end{array}$ & 0.007 \\
\hline Free T4 Q1 & REF & & REF & & REF & & REF & \\
\hline Free T4 Q2 & $\begin{array}{l}-5.79(-10.64 \text { to }- \\
0.94)\end{array}$ & 0.02 & $\begin{array}{l}-4.53(-9.97 \text { to } \\
0.92)\end{array}$ & 0.10 & $\begin{array}{l}107.78(22.24 \\
\text { to } 193.32)\end{array}$ & 0.01 & $\begin{array}{l}89.94(-12.01 \\
\text { to } 191.9)\end{array}$ & 0.08 \\
\hline Free T4 Q3 & $\begin{array}{l}-17.5(-24.58 \text { to }- \\
10.42)\end{array}$ & $<0.001$ & $\begin{array}{l}-15.64(-24.06 \\
\text { to }-7.23)\end{array}$ & $<0.001$ & $\begin{array}{l}282.47(144.1 \\
\text { to } 420.84)\end{array}$ & $<0.001$ & $\begin{array}{l}236.22 \\
(90.14 \text { to } \\
382.3)\end{array}$ & 0.002 \\
\hline Free T4 Q4 & $\begin{array}{l}-7.17(-12.85 \text { to }- \\
1.49)\end{array}$ & 0.01 & $\begin{array}{l}-4.95(-11.13 \text { to } \\
1.24)\end{array}$ & 0.11 & $\begin{array}{l}123.59(29.05 \\
\text { to } 218.12)\end{array}$ & 0.01 & $\begin{array}{l}124.42 \\
(24.06 \text { to } \\
224.78)\end{array}$ & 0.02 \\
\hline
\end{tabular}

Serum T3

(ng/dL)

\begin{tabular}{|c|c|c|c|c|c|c|c|c|}
\hline T3 & $\begin{array}{l}0.09(-0.02 \text { to } \\
0.19)\end{array}$ & 0.09 & $\begin{array}{l}-0.05(-0.17 \text { to } \\
0.07)\end{array}$ & 0.38 & $\begin{array}{l}2.85 \text { (1.16 to } \\
4.54)\end{array}$ & 0.001 & $\begin{array}{l}2.66(0.65 \text { to } \\
4.66)\end{array}$ & 0.01 \\
\hline T3 Q1 & REF & & REF & & REF & & REF & \\
\hline T3 Q2 & $\begin{array}{l}4.35(-1.55 \text { to } \\
10.25)\end{array}$ & 0.14 & $\begin{array}{l}-0.53(-6.72 \text { to } \\
5.67)\end{array}$ & 0.86 & $\begin{array}{l}125.58(40.97 \\
\text { to } 210.19)\end{array}$ & 0.004 & $\begin{array}{l}123.63 \\
(16.77 \text { to } \\
230.49)\end{array}$ & 0.02 \\
\hline T3 Q3 & $\begin{array}{l}5.03(-1.52 \text { to } \\
11.58)\end{array}$ & 0.13 & $\begin{array}{l}0.46(-6.7 \text { to } \\
7.62)\end{array}$ & 0.90 & $\begin{array}{l}58.5(-46.67 \text { to } \\
163.67)\end{array}$ & 0.27 & $\begin{array}{l}68.68(-40.84 \\
\text { to } 178.19)\end{array}$ & 0.21 \\
\hline T3 Q4 & $\begin{array}{l}4.33(-2.74 \text { to } \\
11.39)\end{array}$ & 0.22 & $\begin{array}{l}-3.16(-10.89 \text { to } \\
4.56)\end{array}$ & 0.41 & $\begin{array}{l}176.63 \text { (71.4 to } \\
281.86)\end{array}$ & 0.001 & $\begin{array}{l}160.25 \\
(36.39 \text { to } \\
284.11)\end{array}$ & 0.01 \\
\hline \multicolumn{9}{|l|}{$\begin{array}{l}\text { Serum Free } \\
\text { T3 (pg/mL) }\end{array}$} \\
\hline Free T3 & $\begin{array}{l}6.84(0.8 \text { to } \\
12.88)\end{array}$ & 0.03 & $\begin{array}{l}4.32(-3.71 \text { to } \\
12.36)\end{array}$ & 0.28 & $\begin{array}{l}61.5(-55.48 \text { to } \\
178.48)\end{array}$ & 0.30 & $\begin{array}{l}6.03(-105.51 \\
\text { to } 117.56)\end{array}$ & 0.91 \\
\hline Free T3 Q1 & REF & & REF & & REF & & REF & \\
\hline Free T3 Q2 & $\begin{array}{l}-0.16(-6.76 \text { to } \\
6.44)\end{array}$ & 0.96 & $\begin{array}{l}-1.35(-9.03 \text { to } \\
6.33)\end{array}$ & 0.73 & $\begin{array}{l}121.5 \text { (37.24 to } \\
205.75)\end{array}$ & 0.006 & $\begin{array}{l}116.67(-0.22 \\
\text { to } 233.56)\end{array}$ & 0.05 \\
\hline Free T3 Q3 & $\begin{array}{l}2.31(-4.48 \text { to } \\
9.09)\end{array}$ & 0.50 & $\begin{array}{l}1.88(-5.98 \text { to } \\
9.73)\end{array}$ & 0.63 & $\begin{array}{l}290.15(139.43 \\
\text { to } 440.87)\end{array}$ & $<0.001$ & $\begin{array}{l}118.17 \\
(12.21 \text { to } \\
224.13)\end{array}$ & 0.03 \\
\hline Free T3 Q4 & $\begin{array}{l}4.04(-1.96 \text { to } \\
10.03)\end{array}$ & 0.18 & $\begin{array}{l}0.79(-7.07 \text { to } \\
8.66)\end{array}$ & 0.84 & $\begin{array}{l}131.44(39.53 \\
\text { to } 223.35)\end{array}$ & 0.006 & $\begin{array}{l}56(-60.14 \text { to } \\
172.14)\end{array}$ & 0.34 \\
\hline
\end{tabular}




\section{Cureus}

\section{TABLE 2: Relationship between thyroid hormone profile and platelet count and mean platelet volume}

TSH: thyroid stimulating hormone; T4: L-thyroxine; T3: 3, 3', 5-L-triiodothyronine; Cl: confidence interval; REF: reference quartile

\section{Effect of thyroid hormones on platelet count}

Serum TSH levels were inversely associated with platelet count; each one mIU/L was associated with a decrease in platelet count by 3,353 platelets/uL ( $95 \%$ confidence interval $(\mathrm{CI})=5,451$ $1,255 ; P=0.002)$. Similarly, individuals in the highest quartile of TSH had a significantly lower platelet count than individuals in the lowest quartile (difference $=8,093$ platelets $/ \mathrm{LL} ; 95 \% \mathrm{CI}=$ $13,599-2,587 ; P=0.004)$. On the other hand, each one $\mathrm{ug} / \mathrm{mL}$ of total $\mathrm{T} 4 \mathrm{was}$ associated with an increase in 4,085 platelets/uL $(95 \% \mathrm{CI}=2,898-5,272 ; P<0.001)$. However, there was an inverse relationship between free T4 levels and platelet count; each one $\mathrm{ng} / \mathrm{mL}$ increase in free $\mathrm{T} 4$ was associated with a decrease in 27,842 platelets/uL $(95 \% \mathrm{CI}=8,418-47,265 ; P=0.006)$. Individuals in the highest quartile of total $\mathrm{T} 4$ had a significantly lower platelet count than individuals in the lowest quartile (Table 2). In contrast to total and free T4 levels, serum total T3 levels were not associated with platelet count while free T3 levels were associated with a significant increase in platelet count. Furthermore, there was no difference in platelet count between the quartiles of total T3 or free T3 (Table 2).

After adjustment for potential confounders, the association of TSH levels with platelet count was no longer statistically significant. However, individuals in the highest quartile continued to have a significantly lower platelet count than those in the lowest quartile $(5,826$ platelets/uL; 95\% CI = 10,918-733; $P=0.03$ ). Adjustment for potential confounders did not change the statistically significant association of serum total T4 levels with platelet count and the highest total T4 quartile had a significantly higher platelet count than the lowest quartile. However, free T4, total T3, and free T3 were no longer associated with platelet count after accounting for the effect of confounders (Table 2).

\section{Effect of thyroid hormones on mean platelet volume}

There was no statistically significant relationship between serum TSH levels and MPV and between TSH quartiles and MPV except between the lowest quartile and the second-highest quartile. This relationship between the second-highest quartile and platelet count remained significant even after adjusting for potential confounders suggesting a possible nonlinear relationship. However, the inclusion of a quadratic function in the regression model did not find a significant association between TSH and MPV suggesting that the nonlinear relationship has a more complex shape. In contrast, we found a significant association between both total and free serum T4 levels and MPV which remained significant after adjusting for potential confounders (31 attoliters per ug/dL; 95\% CI = 6.4-55.4; $P=0.01$ and 534 attoliters per ng/dL; 95\% CI $=151.8-971.1 ; P=0.007$, respectively). Individuals in the highest quartiles of total T4 or free T4 had higher MPV than individuals in the lowest quartiles and this relationship remained significant after adjusting for confounders (mean difference $=109.6$ attoliters; $95 \% \mathrm{CI}=1.1$ 218.2; $p=0.05$ and 124.4 attoliters; 95\% CI = 24.1-224.8; $p=0.02$, respectively) (Table 2). Similarly, total T3 levels were significantly associated with an increase in MPV and this relationship remained significant after adjusting for confounders (2.7 attoliters per ng/dL; 95\% $\mathrm{CI}=0.65-4.66 ; P=0.01)$. However, there was no significant linear association between free T3 levels and MPV although a more complex nonlinear relationship was evident from the comparison of quartiles (Table 2). 


\section{Discussion}

In this large sample of a representative noninstitutionalized US adult population without a history of thyroid problems, we found a linear relationship between serum total T4 and platelet indices; an increase in T4 was associated with a rise in platelet count and MPV. On the other hand, free T4 levels and total T3 levels were positively associated with MPV but not with platelet count. Serum TSH levels and free T3 were not independently associated with platelet count or with MPV. Our results show that the relationship between platelet indices and thyroid hormones vary depending on the hormone and whether it is binding in serum.

Our results may appear surprising at first as the serum levels of hypophysis-thyroid axis (HTA) hormones are inter-related and serum levels of one hormone are predictive of serum levels of other hormones within HTA [5]. On the other hand, our findings highlight an interesting relationship between platelet lifespan and the circulation half-life of HTA hormones.

Platelets are anucleate cells and, once produced by megakaryocytes and released from bone marrow into circulation, have a lifespan of 7-10 days [2]. As thyroid hormones act in the nucleus by modulating gene expression, these hormones can only affect platelets indirectly through megakaryocytes. T4, the main hormone secreted by thyroid glands, has a half-life of approximately 5-9 days and its levels may more closely reflect the T4 concentration to which megakaryocytes are exposed at the time of the release of platelets into the circulation [19]. The release of T4 is under the influence of TSH produced by the pituitary gland. Once released in the circulation, T4 undergo deiodination in the peripheral tissues to form T3. Serum TSH and T3 have relatively short half-lives ( 75 minutes and 24 hours, respectively) and their levels may fluctuate widely through the day and under various conditions; hence, one determination of TSH or T3 levels may not be reflective of the true average serum levels present during the formation and lifespan of platelets [5,11].

Previous studies that have examined the effect of thyroid hormones on thrombopoiesis have given inconsistent results [11,20-24]. Studies have either found no relationship or have found an inverse association between thyroid hormone levels and platelet count or MPV [25]. In contrast, we found a robust positive association between serum T4 levels and platelet count and MPV which remained significant after adjusting for potential confounders. This discrepancy between our study results and previous studies may stem from the fact that we excluded individuals with a personal history of thyroid disease while prior studies enrolled mainly individuals with thyroid disease and that these studies were small and thus were likely to not have been powerful to detect the relationship.

The biological mechanism through which T4 can increase platelet count is unclear although it is possible that thyroid hormones will affect both platelet formation as well as prolong the survival of platelets. In one study, bone marrow aspirates from the sternum were obtained from 26 hyperthyroid individuals and 16 healthy individuals [26]. Individuals with hyperthyroidism had a significantly higher number of megakaryocytes in bone marrow aspirates as compared to healthy individuals. One possible mechanism through which thyroid hormones may increase the number of megakaryocytes may include modulation of bone marrow matrix proteins, such as fibronectin. Indeed, in several cell lines, thyroid hormones increase the expression of fibronectin gene. Moreover, individuals with hyperthyroidism have elevated blood levels of fibronectin [27-28]. Fibronectin appears to affect megakaryocyte maturation and thrombopoiesis through interaction with integrin $\alpha 4 \beta 1$ [29]. Apoptosis is the major mechanism through which platelets die and thyroid hormones have been shown to inhibit apoptosis in several cell lines [30].

A major strength of our study is a large sample size representative of the adult US population. 
In addition, all clinical and laboratory variables were collected in a standardized manner. The cross-sectional design of the study is its major limitation, which makes it difficult, if not impossible, to assign a causal relationship between platelet count and serum T4 levels. Further, a single measurement of thyroid hormones may not provide the true thyroid hormone status of an individual over a longer time-period.

\section{Conclusions}

In conclusion, our findings demonstrate that serum total T4 levels are independently associated with increased platelet count and MPV, free T4, and total T3 are independently associated with MPV only, while serum TSH and free T3 levels have no association with either platelet count or MPV. Our study is unable to provide a mechanistic explanation of the observed association. Molecular and animal studies are needed to explore the biological mechanism through which thyroid hormones modulate thrombopoiesis and platelet lifespan.

\section{Additional Information}

\section{Disclosures}

Human subjects: Consent was obtained by all participants in this study. Animal subjects: All authors have confirmed that this study did not involve animal subjects or tissue. Conflicts of interest: In compliance with the ICMJE uniform disclosure form, all authors declare the following: Payment/services info: All authors have declared that no financial support was received from any organization for the submitted work. Financial relationships: All authors have declared that they have no financial relationships at present or within the previous three years with any organizations that might have an interest in the submitted work. Other relationships: All authors have declared that there are no other relationships or activities that could appear to have influenced the submitted work.

\section{References}

1. de Gaetano G: Historical overview of the role of platelets in hemostasis and thrombosis . Haematologica. 2001, 86:349-356.

2. Josefsson EC, White MJ, Dowling MR, Kile BT: Platelet life span and apoptosis. Methods Mol Biol. 2012, 788:59-71. 10.1007/978-1-61779-307-3_5

3. Mason KD, Carpinelli MR, Fletcher JI, et al.: Programmed anuclear cell death delimits platelet life span. Cell. 2007, 128:1173-1186. 10.1016/j.cell.2007.01.037

4. Tata JR: The road to nuclear receptors of thyroid hormone . Biochim Biophys Acta. 2013, 1830:3860-3866. 10.1016/j.bbagen.2012.02.017

5. Beck-Peccoz P, Persani L, Calebiro D, Bonomi M, Mannavola D, Campi I: Syndromes of hormone resistance in the hypothalamic-pituitary-thyroid axis. Best Pract Res Clin Endocrinol Metab. 2006, 20:529-546. 10.1016/j.beem.2006.11.001

6. Cheng SY, Leonard JL, Davis PJ: Molecular aspects of thyroid hormone actions. Endocr Rev. 2010, 31:139-170. 10.1210/er.2009-0007

7. Chute JP, Ross JR, McDonnell DP: Minireview: nuclear receptors, hematopoiesis, and stem cells. Mol Endocrinol. 2010, 24:1-10. 10.1210/me.2009-0332

8. Erikci AA, Karagoz B, Ozturk A, Caglayan S, Ozisik G, Kaygusuz I, Ozata M: The effect of subclinical hypothyroidism on platelet parameters. Hematology. 2009, 14:115-117. 10.1179/102453309X385124

9. Ford HC, Toomath RJ, Carter JM, Delahunt JW, Fagerstrom JN: Mean platelet volume is increased in hyperthyroidism. Am J Hematol. 1988, 27:190-193. 10.1002/ajh.2830270308

10. Stiegler G, Stohlawetz P, Brugger S, Jilma B, Vierhapper H, Hocker P, Panzer S: Elevated numbers of reticulated platelets in hyperthyroidism: direct evidence for an increase of thrombopoiesis. Br J Haematol. 1998, 101:656-658. 10.1046/j.1365-2141.1998.00765.x

11. Panzer S, Haubenstock A, Minar E: Platelets in hyperthyroidism: studies on platelet counts, mean platelet volume, 111-indium-labeled platelet kinetics, and platelet-associated immunoglobulins G and M. J Clin Endocrinol Metab. 1990, 70:491-496. 10.1210/jcem-70-2- 
491

12. NHANES - National Health and Nutrition Examination Survey - CDC . (2018). Accessed: October 8, 2018: https://www.cdc.gov/nchs/nhanes/index.htm.

13. James PA, Oparil S, Carter BL, et al.: Evidence-based guideline for the management of high blood pressure in adults: report from the panel members appointed to the Eighth Joint National Committee (JNC 8). JAMA. 2014, 311:507-520. 10.1001/jama.2013.284427

14. Levey AS, Stevens LA, Schmid CH, et al.: A new equation to estimate glomerular filtration rate. Ann Intern Med. 2009, 150:604-612.

15. Nathan DM, Balkau B, Bonora E, et al.: International expert committee report on the role of the A1C assay in the diagnosis of diabetes. Diabetes Care. 2009, 32:1327-1334. 10.2337/dc099033

16. Fazili Z, Pfeiffer CM, Zhang M: Comparison of serum folate species analyzed by LC-MS/MS with total folate measured by microbiologic assay and Bio-Rad radioassay. Clin Chem. 2007, 53:781-784. 10.1373/clinchem.2006.078451

17. Lee EJ, Oh EJ, Park YJ, Lee HK, Kim BK: Soluble transferrin receptor (sTfR), ferritin, and sTfR/log ferritin index in anemic patients with nonhematologic malignancy and chronic inflammation. Clin Chem. 2002, 48:1118-1121.

18. Le CH: The prevalence of anemia and moderate-severe anemia in the US population (NHANES 2003-2012). PLoS One. 2016, 11:e0166635. 10.1371/journal.pone.0166635

19. Choksi NY, Jahnke GD, St Hilaire C, Shelby M: Role of thyroid hormones in human and laboratory animal reproductive health. Birth Defects Res B Dev Reprod Toxicol. 2003, 68:479491. 10.1002/bdrb.10045

20. Gullu S, Sav H, Kamel N: Effects of levothyroxine treatment on biochemical and hemostasis parameters in patients with hypothyroidism. Eur J Endocrinol. 2005, 152:355-361. 10.1530/eje.1.01857

21. Ioachimescu AG, Makdissi A, Lichtin A, Zimmerman RS: Thyroid disease in patients with idiopathic thrombocytopenia: a cohort study. Thyroid. 2007, 17:1137-1142. 10.1089/thy.2007.0066

22. Kurata Y, Nishioeda Y, Tsubakio T, Kitani T: Thrombocytopenia in Graves' disease: effect of T3 on platelet kinetics. Acta Haematol. 1980, 63:185-190. 10.1159/000207396

23. Sullivan PS, McDonald TP: Thyroxine suppresses thrombocytopoiesis and stimulates erythropoiesis in mice. Proc Soc Exp Biol Med. 1992, 201:271-277. 10.3181/00379727-20143507

24. Stiegler G, Stohlawetz P, Brugger S, Jilma B, Vierhapper H, Hocker P, Panzer S: Thrombopoiesis is increased in hyperthyroidism. J Clin Endocrinol Metab. 1998, 83:1824. 10.1210/jcem.83.5.4821-5

25. Kim JH, Park JH, Kim SY, Bae HY: The mean platelet volume is positively correlated with serum thyrotropin concentrations in a population of healthy subjects and subjects with unsuspected subclinical hypothyroidism. Thyroid. 2013, 23:31-37. 10.1089/thy.2012.0033

26. Axelrod AR, Berman L: The bone marrow in hyperthyroidism and hypothyroidism . Blood. 1951, 6:436-453.

27. Lin KH, Chen CY, Chen SL, et al.: Regulation of fibronectin by thyroid hormone receptors . J Mol Endocrinol. 2004, 33:445-458. 10.1677/jme.1.01505

28. Huang YH, Tsai MM, Lin KH: Thyroid hormone dependent regulation of target genes and their physiological significance. Chang Gung Med J. 2008, 31:325-334.

29. Malara A, Gruppi C, Rebuzzini P, et al.: Megakaryocyte-matrix interaction within bone marrow: new roles for fibronectin and factor XIII-A. Blood. 2011, 117:2476-2483. 10.1182/blood-2010-06-288795

30. Puzianowska-Kuznicka M, Pietrzak M, Turowska O, Nauman A: Thyroid hormones and their receptors in the regulation of cell proliferation. Acta Biochim Pol. 2006, 53:641-650. 